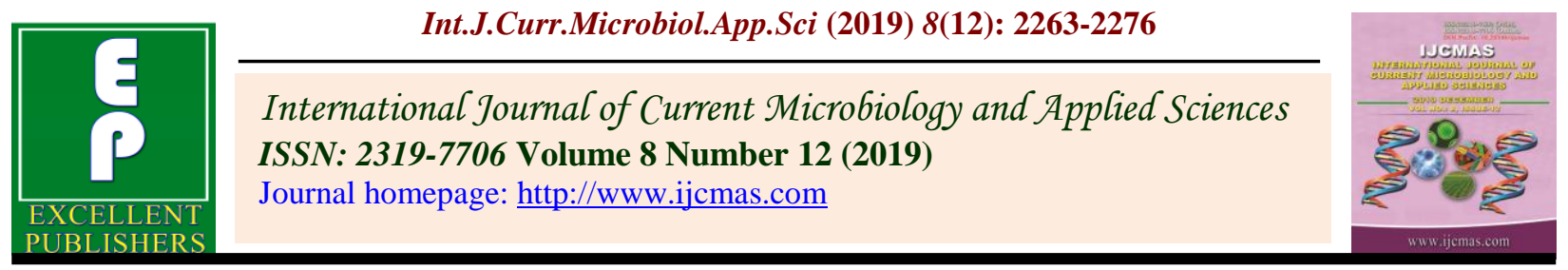

Original Research Article

https://doi.org/10.20546/ijcmas.2019.812.269

\title{
Prevalence of Giardia intestinalis and Cryptosporidium parvum Parasites in Drinking Water in Menoufia Governorate, Egypt
}

\author{
Dalia Shafey ${ }^{1}$, Mohammed M. Aboamer ${ }^{2}$, Karema Abd Elhady Diab ${ }^{3}$, \\ Heba Mohamed Abdallah ${ }^{4}$, Marwa F. Yousef ${ }^{5}$ and Marwa Ahmed Gouda ${ }^{1}$ \\ ${ }^{1}$ Department of Clinical and Molecular parasitology, National Liver Institute (NLI), \\ Menoufia University, Shebin Al Koom, Menoufia, Egypt \\ ${ }^{2}$ Manager of Biology Lab at Tala Holding Company of Water, ${ }^{3}$ Department of Clinical \\ Pathology, ${ }^{4}$ Department of Epidemiology and Preventive Medicine, National Liver \\ Institute(NLI), Menoufia University, Shebin Al Koom, Menoufia, Egypt \\ *Corresponding author
}

\begin{tabular}{|l|}
\hline Ke y w o r d s \\
Cryptosporidium, \\
Giardia, \\
Prevalence, \\
Drinking water, \\
Egypt \\
\hline Article Info \\
\hline Accepted: \\
17 November 2019 \\
Available Online: \\
10 December 2019 \\
\hline
\end{tabular}

\section{A B S T R A C T}

Entero-parasites protozoan of the genera Cryptosporidium and Giardia have emerged over the past decades as major waterborne pathogens with an increasing number of outbreaks reaching over one hundred and sixty. In line with the national goals of providing safe drinking water supplies, this research was designed. We aimed to estimate the prevalence of Cryptosporidium parvum and Giardia intestinalis infections in surface water plants from ShebinAl-Kom and Tala, Menoufia Governorate and to evaluate routine water purification methods used for parasitic elimination. The following methods were used for assessment of samples; mechanical filtration, staining techniques and qPCR assay for detecting DNA of (oo) cysts $n$ water samples. Water samples collected over one year (four seasons) were 87 samples. Microscopic examination (our golden test) revealed, 49 samples positive for cryptosporidium, fourteen positive samples for Giardia and four samples were positive for both of them whereas, qPCR revealed only eight positive samples for Giardia and ten positive samples for cryptosporidium. A statistically significant result concerning seasonal variation was documented where water contamination crested in Summer $(\mathrm{p}<0.05)$. The intensity of infection decreased significantly after water treatment in both Shebin and Tala water stations $(\mathrm{P}=0.01)$.From the present survey, we found that the prevalence of giardiasis and cryptosporidiosis accounted for $29.8 \%$ and $47.1 \%$ in Shebin AlKom and Tala respectively. The parasitic cyst wall structure rendered diagnosis by qPCR. Genotyping of water samples is recommended for sourcing of infection which may be accused of water-borne outbreaks. 


\section{Introduction}

Two billion people at least are estimated worldwide, by World Health Organization (WHO), for the consumption of polluted water and one hundred and forty four millions depend on surface water for their drinking supply. Many diseases are transmitted through water contamination with 485 thousand yearly live loss (WHO, 2019).

Giardia intestinalis (G. intestinalis) and Cryptosporidium parvum (C. parvum) are protozoan parasites that are responsible for widespread gastrointestinal diseases. Some authors reported that water was the main source of about ninety per cent of reported outbreaks by these protozoans, while about $10 \%$ were related to food contamination and person-to-person contact (Heitman et al., 2002), the reported frequencies of surface water contamination with Giardia and Cryptosporidium were from 60 to $96 \%$ in the United States (Nichols et al., 2003) and from 20 to $64 \%$ in Canada (Daley et al., 2018).

Symptoms of infections range from abdominal cramps, headache, nausea, vomiting, lowgrade fever to life-threatening watery diarrhea. The first symptom may appear two to ten days after infection and may last for about two weeks. However, in some individuals, the condition may worsen after recovery. Medical treatment shortens the illness and 50\% of adults get free of infection within one to three months without treatment. It is very important to determine the number of viable(capable of infection) Cryptosporidium oocysts and Giardia cysts to assess the state of infectivity (Chalmers and Davies, 2010).

Incidence of water-borne outbreaks caused by these pathogens was usually underestimated due to their small size and frequently low number excreted in water samples, and the need for well-trained experienced personnel to detect of Cryptosporidium oocysts and Giardia cysts. Therefore, many efforts were made to improve detection methodologies through different techniques such as flow cytometry, laser scanning, immunomagnetic separation, and PCR (Pollock et al., 2008).

Quantitative real-time PCR (qPCR) was applied in the past few years as it provides a great sensitivity in detection plus the ability to estimate quantity of different parasites (Robertson and Gjerde, 2001; Xiao and Fayer, 2008).

In particular, PCR is an attractive diagnostic procedure as being rapid, sensitive, and pathogen-specific. While many PCR methods have been described for both Giardia and Cryptosporidium detection, this technology was slowly emerging as a practical method for pathogen assessment for water quality.

Which may owe to low numbers of cysts and oocysts in water and the requirement of significant sample concentration to reduce large volumes to the quantities suitable for PCR.

The new generation of PCR methods could detect Cryptosporidium and Giardiaspecies that are infective to humans (Xiao and Fayer, 2008).

The ability of Giardia intestinalis and Cryptosporidium parvum to cause waterborne disease is well documented (Wright et al., 2018) However, widely used analytical methods for detecting the presence of these parasites in water didn't provide the quality of data required to assess health risk and effective management of this problem (Weintraub, 2006). Since immunecompromised patients, those with cancer, AIDS, old or very young people are more liable to infection and exaggeration of symptoms and the studied parasites are of 
great concern in developing countries as many governorates in Egypt rely on surface water as a drinking source, therefore it was mandatory to study the prevalence of waterborne protozoa, namely Giardia \& Cryptosporidium, and to give more information which may be lacking in Menoufia Governorate, Egypt.

\section{Materials and Methods}

\section{Study design}

Herein, a cross-sectional study was carried out. Water samples were collected from Shebin Al-Kom and Tala water holding companies, (before, during and after water processing) as representative main centers for water purification in Menoufia Governorate from which health quality samples for the whole Governorate are present over a year from July 2017 to July 2018.

\section{Survey protocol}

Eighty-seven water samples were collected and they were subjected to the following techniques for assessment.

Mechanical filtration of water samples (about $10 \mathrm{~L}$ volume); to maximize (oo)cysts recovery and ensure are presentative sample(Pollock et al., 2008).

Staining with iodine, modified Zeihl Neelsen stain and specific fluorescent antibodies 4',6diamidino-2-phenylindole(DAPI stain); to show the viability of cysts and oocysts.

Counting parasites using differential interference contrast microscopy bySEDGEWICK -RAFTER 50 cell (S.R) slides.

Detection of the parasites by Real-Time PCR (Xiao and Fayer, 2008).

\section{Sample collection}

Water samples were collected from Shebin AlKom and Talawater holding companies, the samples were ten litter each, in a clean labelled plastic container and were mixed with $10 \mathrm{ml}$ of $\mathrm{Na}$ thiosulfate solution (made by adding $3.977 \mathrm{gm}$ of $\mathrm{Na}$ thiosulfate with one litre of distilled water) (Environmental, 2002).Samples were collected every week for the whole year except in winter season where samples were collected nearly every two weeks due to the cold phase stage present in water which renders the presence of organisms in this period (15 samples from both cities were collected through whole the winter season).

\section{Sample processing}

The samples were filtered by a stainless steel filtration unit with a pump, through a membrane filter (cellulose nitrate filter) with pore size $0.45 \mu \mathrm{m}$.

\section{Parasitological examination}

\section{Parasitic counting}

The concentrations of cysts and oocysts stocks were determined with the S.R slide. The cell holds 1000 cubic $\mathrm{ml}$ of liquid one $\mathrm{ml}$ depth over an area of 50x20 ml. The bases were divided into one $\mathrm{ml}$ squares.

A cover glass was used to trap liquid into the correct depth. By observing the liquid through a low magnification microscope, objects contained in each cubic $\mathrm{ml}$ were identified and counted.

\section{Sample staining}

All samples were stained by Lugol's iodine, modified Zeihl-Neelsen, and DAPI stain to assess parasitic viability. 


\section{Microscopy}

Microscopic examination was performed to detect parasites after staining with iodine and Z.N stains. Slides stained with vital stain, DAPI, (Cat No. GTX16206)were examined using a Zeiss Axioskopepi fluorescence microscope fitted with $\mathrm{x} 10$ eyepieces and $\mathrm{x}$ 25 oil and x 100 oil Plan Neofluar objectives, with dichroic mirror and filters for FITC (blue 09), PI (green 15) and DAPI (UV 02). Slides were examined for the presence of (oo)cysts where Cryptosporidium oocysts appeared as spherical shapes with an apple green fluorescence of its wall and a diameter of 4-7 $\mu \mathrm{m}$ and Giardia cysts appeared as oval to spherical shapes with an apple green fluorescence of the wall and a size of 6-15 x 7$18 \mu \mathrm{m}$ (Weintraub, 2006).

\section{Molecular diagnosis by qPCR}

\section{*DNA extraction}

\section{Principle and procedure}

The DNeasy Power Water Kit (Qiagen) (Cat No. 14900-50-NF) began with filtration of a water sample onto a filter membrane which is then added to a special $5 \mathrm{ml}$ bead beating tube containing a unique bead mix. Rapid and thorough lysis occurred through vortexing in a specially formulated lysis buffer that enhanced the isolation of microorganisms from the filter membrane. Freezing and thawing process was done by putting the filtered water samples in liquid nitrogen for two min then transferred to boiling water for two minutes, this process was repeated for five cycles. This step is important to cause the rupture of Giardia cysts and Cryptosporidium oocysts to liberate their DNA contents before DNA extraction to get perfect results (Zhang et al., 2013).

After the protein and inhibitor removal steps, total genomic DNA was captured on an MB
Spin Column. High-quality DNA was then washed and eluted from the MB Spin Column membrane for use in downstream applications including PCR and qPCR, according to the manufacturer's protocol the samples were stored at $-20^{\circ} \mathrm{C}$ until further PCR reactions could be performed (Zhou et al., 2003).

\section{*qPCR}

PCR was carried out using the advanced PCR kit (Genesing Handbook HB04.03.05). Principles of Real-time PCR for C.parvum and G.intestinalis_A-F, specific primer and probe mix was provided and that could be detected through the FAM channel. The primer and probe mix provided exploits the TaqMan ${ }^{\circledR}$ principle. During PCR amplification, forward and reverse primers were hybridized to the C.parvum and G.intestinalis_A-F DNA. A volume of up to $5 \mu \mathrm{l}$ of DNA was used. The Amplification protocol consisted of two minutes of incubation at $95^{\circ} \mathrm{C}$ (for enzymatic activation), followed by 50 cycles of alternating temperatures of $95^{\circ} \mathrm{C}$ for $10 \mathrm{~s}$ (for denaturation) and $60^{\circ} \mathrm{C}$ for one min. (for annealing and extension). A fluorogenic probe was included in the same reaction mixture which consisted of a DNA probe labelled with a 5-dye and a 3 '-quencher. During PCR amplification, the probe was cleaved and the reporter dye and quencher were separated. The resulting increase in fluorescence was detected on a range of qPCR platforms (Xiao, 2010).

\section{Results and Discussion}

Water has a vital role within the transmission of numerous distinctive pathogens such as microbes, and parasites, including Cryptosporidium and Giardia, which are accused of waterborne flaring up of infection (Mons et al., 2009). Prevalence of $G$. intestinalis and $C$. parvum in water samples was evaluated herein. The presence of Giardia cysts and Cryptosporidium oocysts concerning 
the studied geographic areas was assessed by using the microscopic examination of stained specimens (with iodine and modified ZeihlNeelsen stains). Out of 87 water samples prevalence for Giardiasis and cryptosporidiosis was $29.8 \%$ and $47.1 \%$ in Shebin Al-Kom and Tala respectively.

Five positive samples for Giardiasis in Shebin Al-Kom and nine positives for Giardiasis in Tala which represented $35.7 \%$ and $64.3 \%$ of positive cases for Giardiasis. While20 specimens were positive for cryptosporidiosis in Shebin Al-Kom, 29 specimens showed positivity for cryptosporidiosis in Tala with $40.8 \%$ and $59.2 \%$ respectively. Statistical analysis showed a non-significant relation between positive samples and the studied areas $(\mathrm{P}>0.05)$ (Table 1).

Hamdy et al., (2019) in their research on Cryptosporidium and Giardia assessment in Beni-Suef potable water mentioned the prevalence of those two parasites in different Governorates in Egypt. While Giardiasis infection accounted for $36.7 \%, 50 \%, 33 \%$, $13.7 \%, 13 \%$ in Alexandiria, Abo El- nomros, Al Hawamdia, Fayoum, and Gharbia Governorates respectively, cryptosporidiosis prevalence accounted for $100 \%, 50 \%, 52,6 \%$, $12.5 \%, 7.5 \%$ in Alexandiria, Assuit, Fayoum, Elminia, and Gharbia respectively (Hamdy et al., 2019). Similar results were reported worldwide where, Cryptosporidium was detected in $51 \%$ and $25 \%$, while Giardia was detected in $0.62 \%$ and $2.4 \%$ of tap water samples in Jeddah and Makkah respectively (Zakai and Barnawi, 2014). On the other hand, in Iran FeizHadad and his colleagues detected $0 \%$ of both parasites in filter system household tap water samples (Feiz Haddad et al., 2016). In Spain, both parasites were detected in $26.8 \%$ of examined water samples (Carmena et al., 2007).
Studied parasites were counted at different sampling points of water by S.R slide, the number of Giardia and Cryptosporidium parasites respectively in raw water samples was $35(79.5 \%)$ and $200(50.8 \%)$ in Shebin Al-kom and $45(60 \%)$ and $180(60 \%)$ in Tala. After exposure of water to treatment the numbers decreased to reach four $(9 \%)$ and 64 (16.2\%) for Giardia and Cryptosporidium parasites respectively in Shebin Al-kom and $10(13.3 \%)$ and $30(10 \%)$ in Tala. Finally, potable water revealed $5(11.5 \%) \& 130$ (33\%) in Shebin Al-kom and 20 (26.7\%) \& 90 (30\%) Giardia and Cryptosporidium parasites respectively in Tala. A highly significant observation was documented when raw and treated water was compared considering parasite intensity in Shebin Al-Kom station $(\mathrm{P} \leq 0.01)$. From our results it was noticed that the number of parasites decreased in treated water samples then the parasitic number increased again in potable water samples with a significant difference between the two studied stations when raw and treated water were compared with $\mathrm{P}=0.01$. This might raises alarm for a hidden possible route for parasite transmission after successful treatment of water in water purification plants such as contaminated water pipes (Table 2 and Figure 2).

Raw water presented the highest percentage of contamination in our work in comparison to other sampling points. This was in agreement with El-Kowrany and his colleagues, who conducted a similar study in Gharbia Governorate, Egypt and found that the most contaminated sampling points were the raw samples (El-Kowrany et al., 2016). Also, a similar result documented by Antonios et al., (2001), in Dakahlia Governorate, detected the presence of Giardia and Cryptosporidium in potable water samples in $2.1 \%$ and $3.1 \%$ respectively which make water unsafe for human consumption. Similarly, some studies have found that the positive samples were 
often found in raw water samples; for example, in Norway, a survey reported a prevalence of positive parasitic water samples in $16.5 \%$ for Cryptosporidium and $11.5 \%$ of Giardia (Robertson and Gjerde, 2001).

The positivity of all drinking water for Giardiasis and cryptosporidiosis in high percentages was reported by other authors (Shortt et al., 2006).

Quantitative real-time PCR has proven itself to be a faster and a sensitive approach for the detection and enumeration of microorganisms in various environmental samples. A comparison between qPCR method and microscopic examination (after staining)was performed. The highest number of positive samples for Cryptosporidium was observed in raw water 25 samples $(51.0 \%)$ whereas, their positive samples detected by PCR were only two (20.0\%). Also, in Giardiaten positive samples were detected in Raw samples (71.4\%), however, positive samples detected by PCR were five only (62.5\%) (Table 3 and Figure 1).

Our results stated that the number of positive parasitic samples detected by PCR were lower than those detected by microscopy(after staining). These results were in contrast to the finding of Xiao et al., (2006) and Nichols et al., (2003) who reported that the number of positive cases detected by PCR was higher than those detected by microscopic examination.

The fact that the parasitic stages (oo) cysts could stay viable for many months as they are resistant to typical disinfectants(Xiao and Ryan, 2004) and are strong acid resistance because of their specific cell wall structure, as they are covered by thick walls measuring 0.3 to $0.5 \mu \mathrm{m}$ and composed of an outer filamentous layer and an inner membranous layer which is known to be highly resistant to mechanical and chemical disruption (Harris and Petry, 1999) might explain such result. Another possible reason was the failure of complete DNA extraction owing to the need of an increased number of cycles required for freezing and thawing method therefore the DNA remained intact inside the (oo)cysts. Freezing and thawing method was carried out in our work in guidance with Zhang et al., (2013) protocol, five cycles were done for one min in liquid nitrogen and two min in 60c per cycle. On the other side, Nichols et al., (2003) extracted DNA after ten freezing-thawing cycles which consisted of one min in liquid nitrogen and two min in 60c per cycles. This 12- month survey had shown that contamination of water with Cryptosporidium and Giardia (oo)cysts was present throughout the year in surface water (except winter season), with the highest frequency of occurrence reported during the Summer season with $44.9 \%$ for C.parvum and $50.1 \%$ for and G.intestinalis. A second peak for Cryptosporidium was recorded during the Spring, whereas, Giardia's second peak was recorded during the Autumn with a statistically significant difference regarding seasonal variation $(\mathrm{P}<0.05)$ (Table 4). These results were in agreement with that obtained by El-Kowrany et al., (2016)who did a similar study in Gharbia Governorate. Also, similar results were obtained by Siyadatpanah et al., (2018), they studied Giardiasis distribution in Iran.

Climate has a strong impact on the occurrence of protozoan parasites as contaminants in drinking water, especially with extreme weather events. A meta-analysis performed by Young et al., (2014) indicated that the likelihood of the contamination of fresh surface water with Cryptosporidium and Giardia (oo) cysts was significantly increased during extreme weather events, and particularly surface water sources were more liable to contamination during the monsoon season. 
Table.1 Prevalence of Giardia and Cryptosporidium in relation to geographic areas showing presence of parasites in two localities with the total percent of Giardiasis and cryptosporidiosis in relation to the eighty seven examined water samples

\begin{tabular}{|c|c|c|c|c|c|c|c|c|c|c|}
\hline $\begin{array}{c}\text { Geographic } \\
\text { Areas }\end{array}$ & \multicolumn{2}{|c|}{$\begin{array}{c}\text { Positive for } \\
\text { Giardia }\end{array}$} & \multicolumn{2}{|c|}{$\begin{array}{c}\text { Positive for } \\
\text { Crypto }\end{array}$} & \multicolumn{2}{|c|}{$\begin{array}{c}\text { Positive for } \\
\text { both }\end{array}$} & \multicolumn{2}{|c|}{ Total } & $\chi^{2}$ & P. value \\
\hline & No. & $(\%)$ & No. & $(\%)$ & No. & $(\%)$ & No. & $\%$ & & \\
\hline Shebin Al-Kom & 5 & 35.7 & 20 & 40.8 & 1 & 25 & $26 / 87$ & 29.8 & & \\
\hline Tala & 9 & 64.3 & 29 & 59.2 & 3 & 75 & $41 / 87$ & 47.1 & 2.2 & $>\mathbf{0 . 0 5}$ \\
\hline Total & 14 & 100 & 49 & 100 & 4 & 100 & $67 / 87$ & & & \\
\hline
\end{tabular}

Table.2 Demonstrate the results of parasitic counting by S.R slide in relation to sampling point in both water stations

\begin{tabular}{|c|c|c|c|c|c|c|c|c|}
\hline & \multicolumn{3}{|c|}{$\begin{array}{l}\text { Shebin Al-Kom } \\
\text { Sampling point }\end{array}$} & \multicolumn{3}{|c|}{$\begin{array}{c}\text { Tala } \\
\text { Sampling point }\end{array}$} & \multirow[t]{2}{*}{$x^{2}$} & \multirow[t]{2}{*}{$\mathbf{P}$} \\
\hline & Raw & Treated & Potable & Raw & Treated & Potable & & \\
\hline \multicolumn{9}{|c|}{ 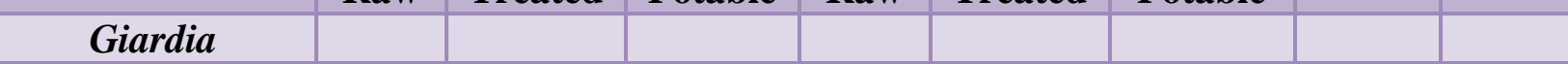 } \\
\hline No. & 35 & 4 & 5 & 45 & 10 & 20 & 6.45 & $\leq 0.05$ \\
\hline$\%$ & 79.5 & 9 & 11.5 & 60 & 13.3 & 26.7 & & \\
\hline \multicolumn{9}{|c|}{ Cryptosporidium } \\
\hline No. & 200 & 64 & 130 & 180 & 30 & 90 & & \\
\hline$\%$ & 50.8 & 16.2 & 33 & 60 & 10 & 30 & & \\
\hline \multicolumn{9}{|c|}{ Statistical analysis } \\
\hline \multicolumn{7}{|c|}{$\begin{array}{l}\text { P1; Comparison between Shebin and Tala regarding Raw and Potable } \\
\text { Water }\end{array}$} & 2.12 & 0.14 \\
\hline \multicolumn{7}{|c|}{$\begin{array}{l}\text { P2; Comparison between Shebin and Tala considering Raw and Treated } \\
\text { Water }\end{array}$} & 6.09 & $0.01 *$ \\
\hline \multicolumn{7}{|c|}{$\begin{array}{c}\text { P3; Shebin Station: Comparison between Raw and Treated ( Highly } \\
\text { Significant ) }\end{array}$} & $\begin{array}{c}\mathrm{Z} \text { test } \\
32.0\end{array}$ & $\begin{array}{c}P \\
\text { value } \\
\leq 0.01\end{array}$ \\
\hline \multicolumn{7}{|c|}{ P4; Shebin Station: Comparison between Potable and treated. } & 0.1 & $>0.05$ \\
\hline \multicolumn{7}{|c|}{ P5; Shebin Station: Comparison between Raw and potable. } & & $>0.05$ \\
\hline \multicolumn{7}{|c|}{$\begin{array}{l}\text { P6; Tala: Raw and Treated, Raw and potable and Potable and Treated } \\
\text { water }\end{array}$} & & $>0.05$ \\
\hline
\end{tabular}

"Refer to highly statistically significant $\mathrm{P}$ value. 
Table.3 Comparison between results of PCR and Microscopic examination in relation to the type of water samples

\begin{tabular}{|c|c|c|c|c|c|}
\hline \multirow[t]{2}{*}{ Sample } & \multicolumn{3}{|c|}{ Microscopy } & \multicolumn{2}{|c|}{ PCR Results } \\
\hline & Both & Cryptosporidium & Giardia & Giardia & Cryptosporidium \\
\hline Raw & $\begin{array}{c}1 \\
(25)\end{array}$ & $25(51.0)$ & $\begin{array}{c}10 \\
(71.4)\end{array}$ & $5(62.5)$ & $2(20.0)$ \\
\hline Treated & $\begin{array}{c}2 \\
(50)\end{array}$ & $4 \quad(8.2)$ & $0 \quad(0.0)$ & $0(0.0)$ & $4(40.0)$ \\
\hline Potable & $\begin{array}{c}1 \\
(25)\end{array}$ & $20(40.8)$ & $4 \quad(28.6)$ & $3 \quad(37.5)$ & $4(40.0)$ \\
\hline & 4 & 49 & 14 & 8 & 10 \\
\hline
\end{tabular}

Table.4 Distribution of infection detected in positive samples examined by Z.N and Iodine Stains for Giardia and Cryptosporidium in Relation to the Seasons

\begin{tabular}{|c|c|c|c|c|c|c|c|}
\hline & \multicolumn{4}{|c|}{ Season } & \multirow[b]{2}{*}{ Total } & \multirow[t]{2}{*}{$\chi^{2}$} & \multirow[t]{2}{*}{$\mathbf{P}$} \\
\hline & Summer & Autumn & Winter & Spring & & & \\
\hline \multicolumn{8}{|c|}{ - } \\
\hline No. & 7 & 6 & 0 & 1 & 14 & 28.1 & $<0.05$ \\
\hline$\%$ & 50 & 42.9 & 0.0 & 7.1 & 21.0 & & \\
\hline \multicolumn{8}{|c|}{ Cryptosporidium } \\
\hline No. & 22 & 9 & 2 & 16 & 49 & & \\
\hline$\%$ & 44.9 & 18.4 & 4.0 & 32.7 & 73.1 & & \\
\hline \multicolumn{8}{|c|}{ Both parasites } \\
\hline No. & 4 & 0 & 0 & 0 & 4 & & \\
\hline$\%$ & 100 & 0.0 & 0.0 & 0.0 & 5.9 & & \\
\hline \multicolumn{8}{|c|}{ Total } \\
\hline No. & 33 & 15 & 2 & 17 & & & \\
\hline$\%$ & 49.2 & 22.4 & 3.0 & 25.4 & & & \\
\hline
\end{tabular}


Fig.1 Showing detection of qPCR results for detecting $G$. intestinalis and $C$. parvum in water samples. The standard curves (A, B, C \& D) and the amplification plots (E \& F) were presented

A; Run 1 for G. .intestinalis

B; Run 1 for C. parvum

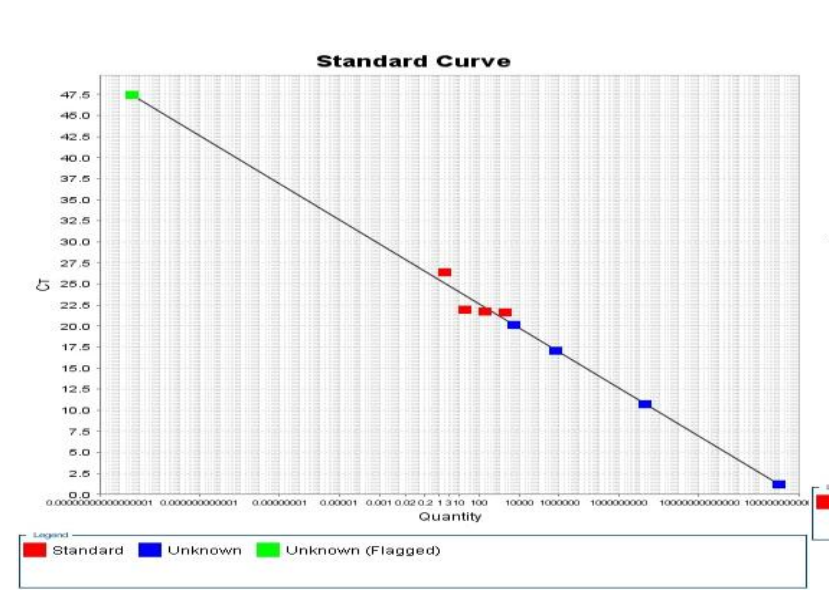

C; Run 2 for $G$.intestinalis

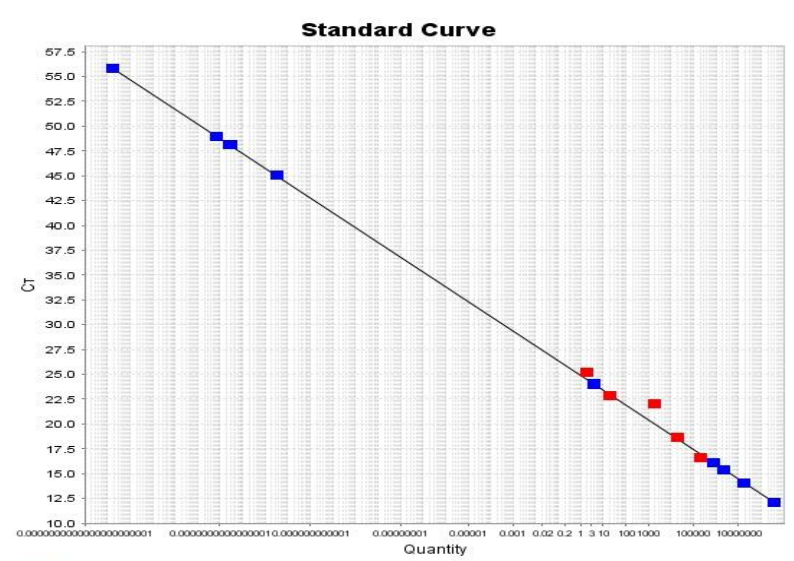

Standard Unknown Unknown (Flagged)

E; Run 1 for G.intestinalis

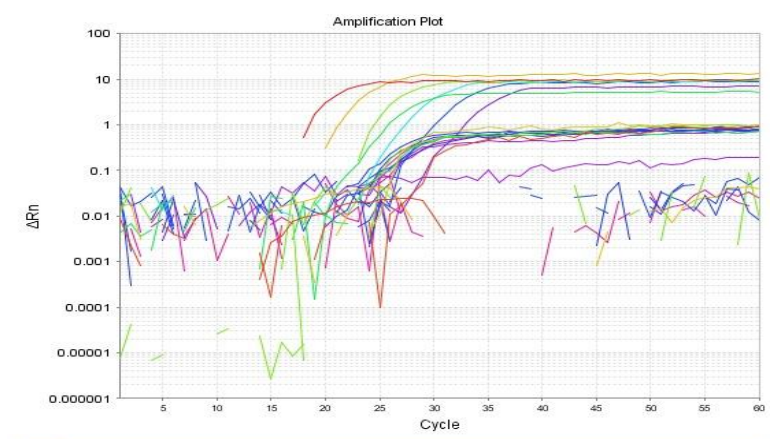

$\left[\begin{array}{l}\mathrm{L} \text { A } \\ \mathrm{B}\end{array}\right.$

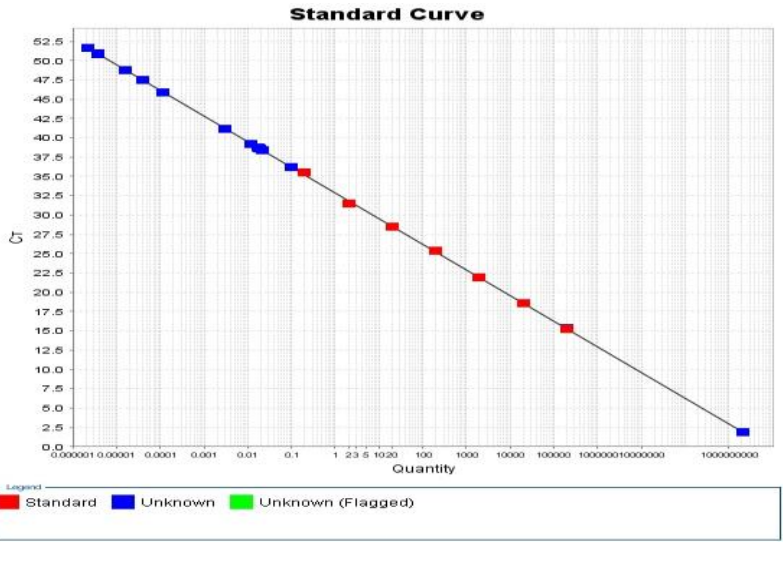

D; Run 2 for C.parvum

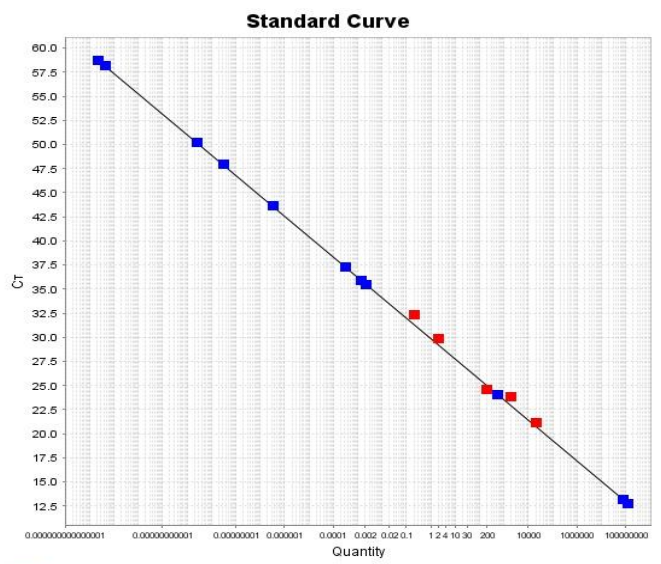

Standard Unknown Unknown (Flagged)

F; Run 1 for $C$. parvum

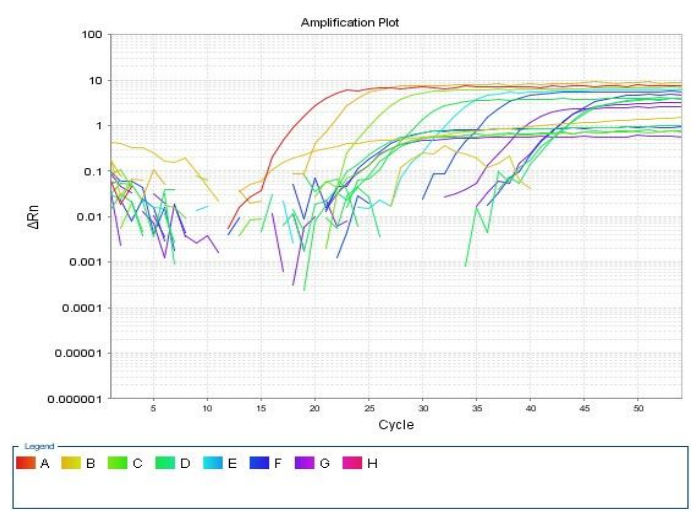


Fig.2 Show Cryptosporidium and Giardia with different stains. A; Showing Cryptosporidium oocysts appearing as spherical shapes with apple green fluorescence in its wall by using fluorescent microscopy. B; Cryptosporidium is shown under S.R slides used for counting the parasite under light microscopy (x1000).C; Wet mounting for water samples showing Giardia cyst by light microscopy (x1000). D; Wet mounting for water samples showing Cryptosporidium oocysts by light microscopy (x1000). E \&F; shows Cryptosporidium oocysts stained by modified Ziehl Nelseen stain (x1000)
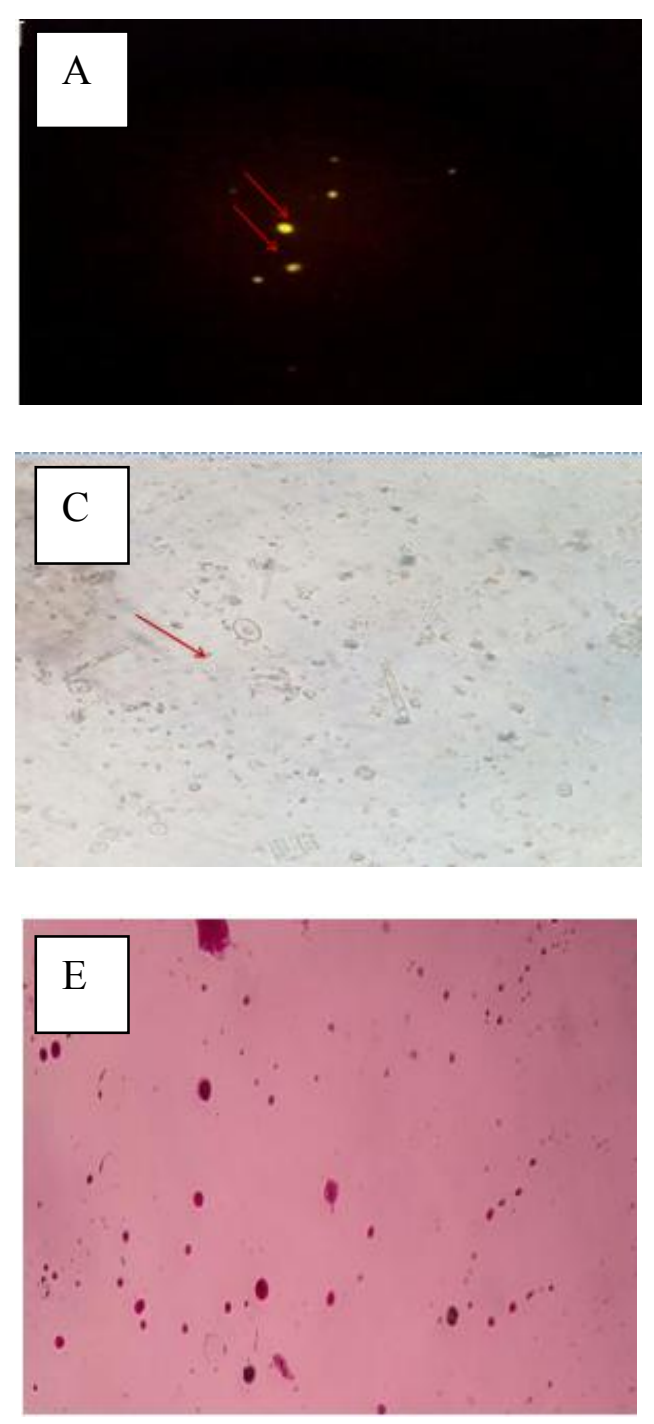
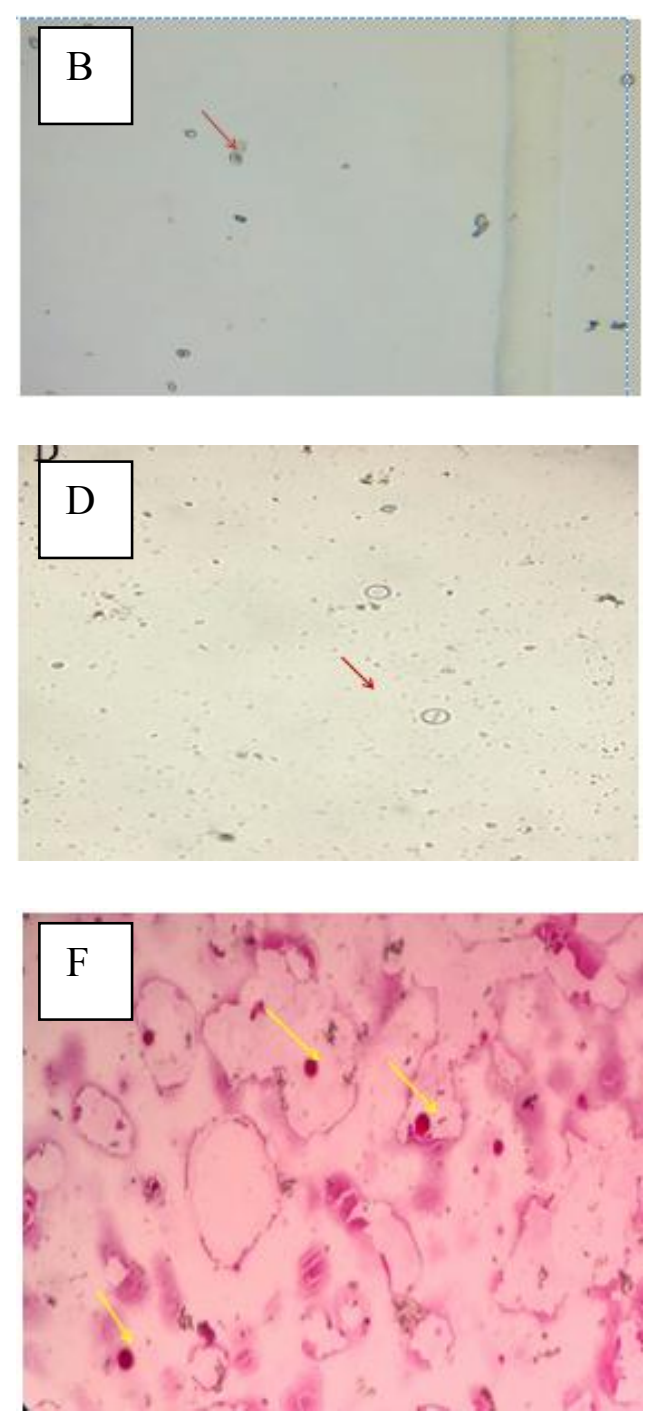
Fig.3 Showing other parasites detected during water examination. A; Cyclotella algae (which resembles Cryptosporidium oocysts and was differentiated by its inability to take acid fast stain) x1000. B; Toxocara found in water samples under S.R. slide (x1000)

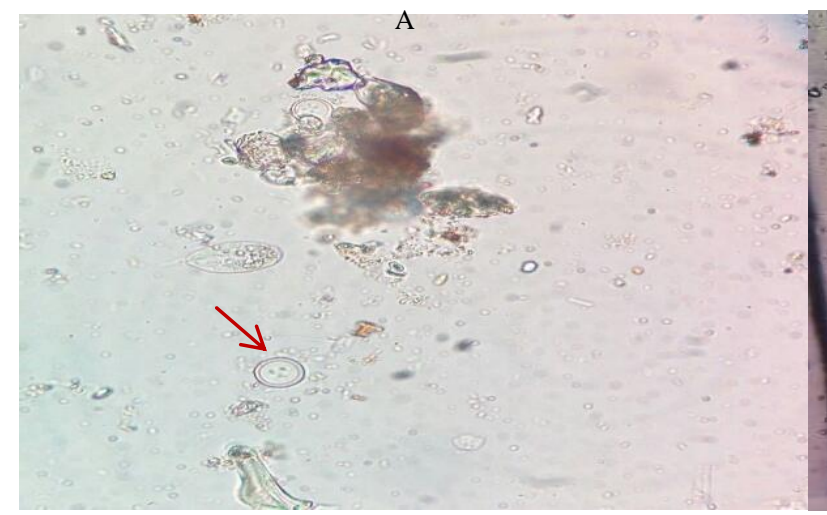

Thus, an increase in water contamination is more likely expected in this period of the year (Masina et al., 2019). They also, reported that there was significant relationship between the presence of both parasites in water and seasonal variations.

In our study, one of the main concerns was the high percentage of $C$. parvum (oo) cysts viability (by using DAPI stain) found in potable water samples this may lead to endemic transmission of water-borne parasitic infections.

Cyclotella algae and Toxocara were found under microscopy during the examination of surface water samples and documented in Figure 3. Cyclotella importance came from being similar to Giardia and Cryptosporidium fluorescence, after being stained with the IFA reagents as they exhibit a green fluorescence. The presence of fluorescent organisms similar in size and shape to Giardia and Cryptosporidium organisms increases the likelihood of false-positive results (Rodgers et al., 1995).

Toxocariasis is an infection caused by the ingestion of larvae of the dog roundworm Toxocaracanis or the cat roundworm Toxocaracati. They may contaminate water and cause human disease that involves the liver, heart, lung, muscle, eye, and brain. It could be transferred through water (Beer et al., 1999).

Our study provided data about the prevalence of Giardiasis and cryptosporidiosis in both Tala and Shebin Al-kom water stations as representative of Menoufia Governorate which would provide a database in order to control this public health problem in water supplies.

We found that they are consistently present at high concentrations in raw and potable water samples.

The presence of this high percentage of $C$. parvum viable oocysts in potable water (by using DAPI stain) needs more attention being considered as a risk factor for endemic transmission of water-borne parasitic infections.

The best method for cyst wall lysis should also be documented. Finally, genotyping of examined water samples is recommended to identify the source of infection.

\section{Compliance with ethics requirements}

This article does not contain any studies with human or animal subjects. However, health education about water contamination and 
possible transmitted diseases was done to individuals found in the survey time to minimize risk factors for infections.

\section{Financial assistance}

This research was authorized by Menoufia University research unit and supported by a Project fully funded.

\section{Acknowledgment}

The authors are grateful to Collaborative Research Center, National Liver Institute. The authors are thankful to Dr/ HeshamAbdeldayem (NLI dean) for his support and facilitating our work in NLI laboratories.

\section{References}

Antonios, S N, S A Salem, and E A Khalifa. 2001. "Water Pollution Is a Risk Factor for Cryptosporidium Infection in Gharbia Governorate." Journal of the Egyptian Society of Parasitology 31(3): 963.

Beer, S A, G I Novosil'tsev, and L I Mel'nikova. 1999. "The Role of the Water Factor in the Dissemination of Toxocara Eggs and the Spread of Toxocariasis in a Megalopolis." Parazitologiia 33(2): 129-35.

Carmena, D, X Aguinagalde, C Zigorraga, J C Fernández- Crespo, and J A Ocio. 2007. "Presence of Giardia Cysts and Cryptosporidium Oocysts in Drinking Water Supplies in Northern Spain." Journal of Applied Microbiology 102(3): 619-29.

Chalmers, Rachel M, and Angharad P Davies. 2010. "Minireview: Clinical Cryptosporidiosis." Experimental Parasitology 124 (1): 138-46.

Daley, Kiley, Lisbeth Truelstrup Hansen, Rob C Jamieson, Jenny L Hayward, Greg S Piorkowski, Wendy Krkosek, Graham
A Gagnon, Heather Castleden, Kristen MacNeil, and Joanna Poltarowicz. 2018. "Chemical and Microbial Characteristics of Municipal Drinking Water Supply Systems in the Canadian Arctic." Environmental Science and Pollution Research 25 (33): 32926-37.

El-Kowrany, Samy I, Enas A El-Zamarany, Kholoud A El-Nouby, Dalia A ElMehy, Ehab A Abo Ali, Ahmad A Othman, Wesam Salah, and Ahmad A El-Ebiary. 2016. "Water Pollution in the Middle Nile Delta, Egypt: An Environmental Study." Journal of Advanced Research 7 (5): 781-94.

Environmental, Protection Agency E P A. 2002. "National Primary Drinking Water Regulations: Long Term 1 Enhanced Surface Water Treatment Rule. Final Rule." Federal Register 67 (9): 1811.

Feiz Haddad, M H, A Karamkhani, and R Feiz Haddad. 2016. "Waterborne Parasites: A Recent Status of Occurrence, Source and Human Intestinal Parasites in Sources and Tap Water; Dehloran, South West, Iran.” Allergy, Drugs and Clinical Immunology 1 (1): 18-21.

Hamdy, Doaa, Ayman El-Badry, and Wegdan A B D EL WAHAB. 2019. "Assessment of Giardia and Cryptosporidium Assemblages/Species and Their Viability in Potable Tap Water in Beni-Suef, Egypt Using Nested PCR/RFLP and Staining." Iranian Journal of Parasitology 14 (3): 368.

Harris, J Robin, and Franz Petry. 1999. "Cryptosporidium Parvum: Structural Components of the Oocyst Wall." The Journal of Parasitology, 839-49.

Heitman, T L, L M Frederick, J R Viste, N J Guselle, U M Morgan, R C A Thompson, and M E Olson. 2002. "Prevalence of Giardia and Cryptosporidium and Characterization 
of Cryptosporidium Spp. Isolated from Wildlife, Human, and Agricultural Sources in the North Saskatchewan River Basin in Alberta, Canada." Canadian Journal of Microbiology 48 (6): 530-41.

Masina, Stephanie, Jamal Shirley, Jean Allen, Jan M Sargeant, Rebecca A Guy, Peter M Wallis, J Scott Weese, Ashlee Cunsolo, Anna Bunce, and Sherilee L Harper. $2019 . \quad$ "Weather, Environmental Conditions, and Waterborne Giardia and Cryptosporidium in Iqaluit, Nunavut." Journal of Water and Health 17 (1): 84-97.

Mons, Céline, Aurélien Dumètre, Sylvie Gosselin, Christelle Galliot, and Laurent Moulin. 2009. "Monitoring of Cryptosporidium and Giardia River Contamination in Paris Area." Water Research 43 (1): 211-17.

Nichols, R A B, B M Campbell, and H V Smith. 2003. "Identification of Cryptosporidium Spp. Oocysts in United Kingdom Noncarbonated Natural Mineral Waters and Drinking Waters by Using a Modified Nested PCR-Restriction Fragment Length Polymorphism Assay." Appl. Environ. Microbiol.69 (7): 4183-89.

Pollock, Kevin G J, David Young, Huw V Smith, and Colin N Ramsay. 2008. "Cryptosporidiosis and Filtration of Water from Loch Lomond, Scotland." Emerging Infectious Diseases 14 (1): 115.

Robertson, L J, and B Gjerde. 2001. "Occurrence of Parasites on Fruits and Vegetables in Norway." Journal of Food Protection 64 (11): 1793-98.

Rodgers, Mark R, Debbie J Flanigan, and Walter Jakubowski. 1995. "Identification of Algae Which Interfere with the Detection of Giardia Cysts and Cryptosporidium Oocysts and a Method for Alleviating This Interference." Appl. Environ. Microbiol. 61 (10): 3759-63.

Shortt, Rebecca L, Eline Boelee, Yutaka Matsuno, Chandra Madramootoo, Wim Van Der Hoek, and Gaetan Faubert. 2006. "Cryptosporidium and Giardia as Determinants for Selection of an Appropriate Source of DrinkingWater in Southern Sri Lanka." Journal of Health, Population and Nutrition, 64-70.

Siyadatpanah, Abolghasem, Mehdi Sharif, Ahmad Daryani, Shahabeddin Sarvi, Mohammad Hasan Kohansal, Saeed Barzegari, Abdol Sattar Pagheh, and Shirzad Gholami. 2018. "Spatial Distribution of Giardia Lamblia Infection among General Population in Mazandaran Province, North of Iran." Journal of Parasitic Diseases 42 (2): 171-76.

Weintraub, June M. 2006. "Improving Cryptosporidium Testing Methods: A Public Health Perspective." Journal of Water and Health 4 (S1): 23-26.

Wright, Carlee J, Jan M Sargeant, Victoria L Edge, James D Ford, Khosrow Farahbakhsh, Inez Shiwak, Charlie Flowers, Sherilee L Harper, and IHACC Research Team. 2018. "Water Quality and Health in Northern Canada: Stored Drinking Water and Acute Gastrointestinal Illness in Labrador Inuit." Environmental Science and Pollution Research 25 (33): 32975-87.

Xiao, Lihua. 2010. "Molecular Epidemiology of Cryptosporidiosis: An Update." Experimental Parasitology 124 (1): 80-89.

Xiao, Lihua, Kerri A Alderisio, and Jianlin Jiang. 2006. "Detection of Cryptosporidium Oocysts in Water: Effect of the Number of Samples and Analytic Replicates on Test Results." 
Appl. Environ. Microbiol. 72 (9): 5942-47.

Xiao, Lihua, and Ronald Fayer. 2008. "Molecular Characterisation of Species and Genotypes of Cryptosporidium and Giardia and Assessment of Zoonotic Transmission." International Journal for Parasitology 38 (11): 1239-55.

Xiao, Lihua, and Una M Ryan. 2004. "Cryptosporidiosis: An Update in Molecular Epidemiology." Current Opinion in Infectious Diseases 17 (5): 483-90.

Young, Ian, Ben A Smith, and Aamir Fazil. 2014. "A Systematic Review and Meta-Analysis of the Effects of Extreme Weather Events and Other Weather-Related Variables on Cryptosporidium and Giardia in Fresh Surface Waters." Journal of Water and Health 13 (1): 1-17.

Zakai, Haytham Ahmed, and Hanadi Ibraheem
Barnawi. 2014. "Prevalence of Cryptosporidium and Giardia Lamblia in Water Samples from Jeddah and Makkah Cities." Journal of Advanced Laboratory Research in Biology 5 (1).

Zhang, Huining, Xiaohu Zhang, Shuting Zhang, Bo Wei, Qipei Jiang, and Xin Yu. 2013. "Detecting Cryptosporidium Parvum and Giardia Lamblia by Coagulation Concentration and RealTime PCR Quantification." Frontiers of Environmental Science \& Engineering 7 (1): 49-54.

Zhou, Ling, Ajaib Singh, Jianlin Jiang, and Lihua Xiao. 2003. "Molecular Surveillance of Cryptosporidium Spp. in Raw Wastewater in Milwaukee: Implications for Understanding Outbreak Occurrence and Transmission Dynamics." Journal of Clinical Microbiology 41 (11): 525457.

\section{How to cite this article:}

Dalia Shafey, Mohammed M. Aboamer, Karema Abd Elhady Diab, Heba Mohamed Abdallah, Marwa F. Yousef and Marwa Ahmed Gouda. 2019. Prevalence of Giardia intestinalis and Cryptosporidium parvum Parasites in Drinking Water in Menoufia Governorate, Egypt. Int.J.Curr.Microbiol.App.Sci. 8(12): 2263-2276. doi: https://doi.org/10.20546/ijcmas.2019.812.269 